\title{
Developing Cross-Disciplinary Competencies through College Algebra
}

\author{
Reem Jaafar, PhD \\ Assistant Professor, Department of Mathematics, Engineering and Computer Science \\ LaGuardia Community College, C.U.N.Y \\ Yelena Baishanski, PhD \\ Assistant Professor, Department of Mathematics, Engineering and Computer Science \\ LaGuardia Community College, C.U.N.Y
}

To argue for the importance of an integrative approach to learning in introductory STEM (Science, Technology, Engineering and Mathematics) and other courses, we present a case study of a project incorporating cross-curricular skills in a college algebra course. We analyze student work on the project and responses to surveys, and find the assignment affects positively students' mastery of specific quantitative skills, perceptions of learning, civic awareness, and sense of relevance of mathematical study. We use the analysis to suggest guidelines for designing other activities aiming to teach the whole student in introductory courses.

At LaGuardia Community College, where the large urban student body is composed mostly of first-generation college-goers, the mission is "to educate and graduate one of the most diverse student populations in the country to become critical thinkers and socially responsible citizens who help to shape a rapidly evolving society" (Mission Statement). Faculty members try to make undergraduate education a

...Project Quantum Leap (PQL) was launched to help students learn math through compelling socio-cultural contexts.

transformative experience for students, one that develops and enriches the whole person. We constantly seek to infuse our courses with materials that address the mission of the college, and that revolve around its five stated "core competencies": critical literacy, quantitative reasoning, oral communication, research and information literacy, and technological literacy. As mathematics faculty in particular, we strive to enact in our courses the philosophy articulated by The Carnegie Foundation for the Advancement of Teaching, that "community college students will have greater motivation to succeed and persist if their mathematics study is engaging, meaningful, relevant and useful" (Quantway).

As one of many LaGuardia initiatives aiming to address the core competencies and heighten student engagement, Project Quantum Leap (PQL) was launched to help students learn math through compelling socio-cultural contexts. An adaptation to introductory-level mathematics courses of Science Education for New Civic Engagements and Responsibilities (SENCER) pedagogies nationally recognized and funded by the National Science Foundation, PQL has yielded many facultydeveloped projects that integrate online research, critical reading, math exercises, and analysis of quantitative results into student reflections (Betne, 2010).

In this paper, we present a case study of a PQL project focusing on food and commodity prices. We examine its effect on student learning in an introductory college algebra course, viewed as central in any mathematics curriculum, and as the boundary between high school and college (Steen, 2004, p. 38). We analyze students' work and survey responses to see how the project helps reinforce LaGuardia's core competencies, and we use the analysis to suggest guidelines for activities aiming to teach the whole student.

InSight: A J ournal of Scholarly Teaching 


\section{The Scholarship of Teaching and Learning and Learning Goals}

This work has been greatly inspired by the Scholarship of Teaching and Learning (SOTL) movement. In The Advancement of Learning, Huber and Hutchings (2005) state that the Scholarship of Teaching and Learning should not be viewed as a fix to something that has gone wrong, but as "a set of habits and dispositions for meeting the challenges that we all face as learners" (p. 1), and illustrate transformational "dispositions" with several examples of faculty pedagogies across the curriculum. Professor Curtis Bennett in Mathematics, for example, wanting each of his students to "think like a mathematician," redesigned his course to allow students "to create definitions, to refine mathematical problems, and to become owners and creators of mathematics" (p. 38). Lee Shulman's (2005) concept of "pedagogical signatures" allows for further exploration of the significance and impact of teaching habits. The "signature" lecture format and board full of equations of an engineering course, like the key bedside training component of a nursing course, not only provide insight into how knowledge is analyzed or accepted in a given field, but also enlighten us as to the limitations signature pedagogies can impose on educators from each field (Shulman, 2005). The identification of different habitual transmissions of knowledge, by inviting us to reconsider "knowledge" itself, allows us to reevaluate our role as educators, and to explore alternative, potentially more effective means of generating understanding in an audience of non-specialist students.

Drawing on Boyer's (1990) "scholarship of integration" (p. 18), we aim in this project to adapt the traditional signature pedagogy of mathematics to students' needs; we want to enable students to become "owners and creators" of knowledge that bridges disciplines and competencies. Through the project, students are expected to deduce the meaning of specialized vocabulary from context, compare their understanding to definitions, familiarize themselves with the many factors affecting a civic issue, and explore mathematical concepts through hands-on examination of real-world data. In addition to educating students about political and economic factors responsible for social orders, the project incorporates targeted mathematical learning goals. It guides students to understand and apply the concepts of average rate of change; graph various data; fit them to given models; predict future values using these mathematical models; and use numbers, graphs, and facts to argue a position.

\section{Project Description}

The project consists of eight questions (see appendix). In questions 1 and 2 , students are asked to research online various definitions and technical terms regarding commodities and trading. Having students find the definitions of various terms aims to reinforce critical literacy as well as research and information literacy, since they are called upon to judge whether the obtained information and sources used are reliable. Questions 3 and 4 test students' understanding of two articles explaining global spikes in the prices of food staples, and prepare them for the indepth investigation of question 5 , which links mathematical concepts to real-world data and the issues tackled in the articles. Students are first asked to determine various rates of change based on graphs of current commodity price fluctuations. To hone their quantitative reasoning and critical thinking skills, they are then required to evaluate the validity of competing claims purportedly based on the given data, and to use their mathematical results to establish and argue their own position.

Whether students take introductory college algebra as their first course in college or after completing developmental mathematics courses, it is crucial that all master ever-more powerful technological tools, and be able to manipulate these to interpret and draw conclusions from factual data. By having students use Excel to graph real data and build predictive models, question 6 aims to build on mathematical understanding while developing technological literacy. Finally, 
questions 7 and 8 seek to reinforce critical literacy by having students write an essay using mathematical arguments and various facts stated in the articles. These two final questions also aim at creating engaged and concerned citizens.

\section{Assessment and Survey Results}

After approval by LaGuardia's Institutional Review Board, anonymous surveys were distributed to three sections of College Algebra and Trigonometry to complement instructor assessment and provide a fuller picture of student learning. Students used their own words to describe what they learned, the project features they found most or least interesting, how they evaluated the reliability of websites used to research definitions, and how they would modify the project if given the opportunity. In the remaining 7 out of 12 survey questions, students used a scale of 1 to 5 to evaluate changes in their awareness, confidence, and specific abilities before and after completing the project (where 1 meant "no improvement at all" and 5 indicated "very strong improvement").

Clear trends emerge from the data compiled from 55 survey responses. The first, illustrated in Figure 1 below, suggests significant gains in those quantitative reasoning aptitudes specifically targeted by the project. Over half and two-thirds of the respondents, respectively, reported strong improvement (4-5) in their abilities to interpret graphical data, and to graph a given function using Excel-skills that were heavily called on in the project. (The proportions of students reporting overall improvement in these aptitudes-ratings of 3 or above-rise to yet more significant $73 \%$ and $90 \%$, respectively.) Other skills, such as sketching a function by hand, or communicating with mathematical notations and symbols, were exercised in class lessons, homework, and class discussions of the project, but were not explicitly targeted by the project exercises. While a majority of students noted overall improvement in these areas, only $35 \%$ and $20 \%$ of respondents, respectively, indicated strong improvement in these two categories.

Figure 1: Student Perceptions of I mprovement

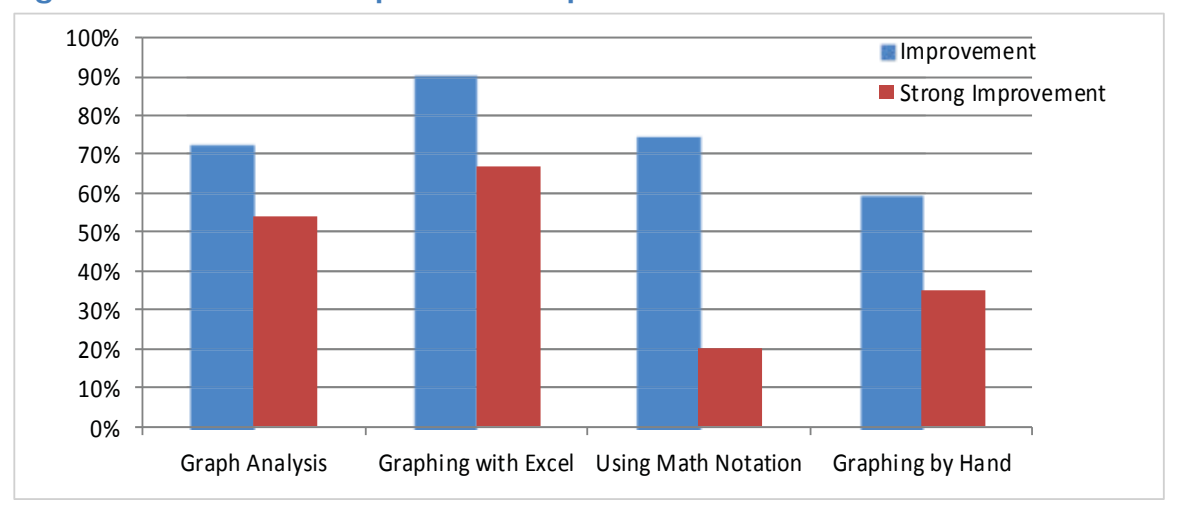

Skills Targeted by Project Skills Not Explicitly Targeted by Project

The survey responses further suggest that linking the practice of quantitative reasoning skills to exploration and research of social issues may raise civic awareness and engagement. While a significant $80 \%$ of respondents indicated little to no awareness of factors affecting food prices prior to their work on the project, with $40 \%$ reporting "no awareness at all," the overall impact of the project 
went beyond raising awareness: $85 \%$ of respondents indicated that the learning activity affected their social concerns, and $60 \%$ reported they were "strongly affected." The project's influence on student awareness of political and economic issues is further reflected in the free-response summaries of their learning: Indeed, 51 of the 55 respondents stressed learning other content besides quantitative reasoning skills or concepts, mentioning "new words and their meanings"; "how trading works and how it affects the economy"; "what commodities actually are"; that "the US deregulated food commodity trading"; that "there are forces outside of supply and demand that affect prices on the commodities market"; that "corporations can single-handedly affect (sic) a spike/rise in a price"; and that "starving in other countries may not be [due] to lack of food [but] rather to an escalation in food prices due to speculation."

Analysis of what students found most interesting in the project reveals a roughly even split between those who preferred the information and analysis provided by the readings, and those who preferred the study and use of online graphs and data to create predictive models in Excel. These results reflect the variety of student interests and learning styles accommodated by the project's integrative approach. The results concerning what students found least interesting also concentrated around two main themes: Almost $60 \%$ of students stated that researching and giving definitions was uninteresting, while nearly $40 \%$ expressed lack of interest in graph construction. Very few (less than 6\%) expressed frustration at having to read or write in a math class.

Instructors were pleased with students' mathematical results: Nearly all students, thanks to project and instructor guidelines, were able to not only compute rates of change-a traditionally challenging concept for this classroom populationbut also to correctly use it to predict future prices; and in spite of some students' lack of interest in graphing data, nearly all were also able to fit data to appropriate predictive models. Students also demonstrated good understanding of the two assigned readings through their responses to project questions 3 and 4 . However, for all the advantages that instructor assessment and survey responses indicate, the project also reveals some drawbacks. Although question 7 specifically asked students to include data and quantitative analyses to argue their positions, students did not integrate mathematical results or observations in defense of any of their claims. In fact, students' responses were impassioned and tended to forgo argument altogether, as in the following typical example:

It shocks me how these investors look for anyway to profit even if it's at the expense of others. I think the government need to pay more attention to these speculators because their causing so much economic problems. If the government monitors this then the high increase in commodities can be avoided. I think people should have a say in how food is priced because in the end it's the people who have to buy it. (...) The people to blame are the investors who take advantage of their position and only seek their own selfish desires. Commodities should be regulated since these traders cannot decide on a reasonable price for everyone.

Such writing, impassioned but falling short of argumentative defense, illustrates 'the extent to which students' prior understandings of a field situate a person to acquire new knowledge" (Bass, 1999, p. 5). Particular care needs to be taken, through classroom discussions and feedback, to prepare students to transition from their strong positions, and their assumptions about what constitutes reasoned argument, to the use of quantitative and qualitative defenses of a claim, based on data and documented facts.

The impatience that students expressed in the surveys with researching and formulating definitions shed light on another problem that instructors regularly came across in their assessment. Students betrayed uncertainty in their use of

Volume $7 \bullet 2012$ 
technical terminology and occasionally confused definitions and meanings, such as those of "regulation" and "deregulation". One student argued against the usefulness of formulating definitions for terms, "I found them more interesting and understandable in the article than defining them myself." This discovery of confusion and attendant frustration, however, represents a real teaching opportunity. While the project failed to transmit to students the relevance of definitions, the student's own comment points to the remedy; if challenged as a group to translate their understanding from context to definitions (and only then to compare their definitions to formal ones), students might experience, along with the ambiguity and difficulty of creating and transmitting knowledge, the richness of exploration and discovery their effort provides.

\section{Recommendations}

In SOTL, teaching has four defining features: questioning, gathering and exploring evidence, trying out and refining new insights, and going public (Huber \& Hutchings, 2005, p. 20-29). The insights gained from analysis of students' work lead us to suggest certain improvements in implementing cross disciplinary projects. As students in introductory courses in all fields struggle to make an argument, we recommend scaffolding and further refining guidelines to argumentative writing tasks (such as question 7). For our purposes, for example, improved guidelines will involve stressing the requirement to incorporate in argument at least two results from previous computations; the inclusion, for comparison, of sample essays illustrating both effective and ineffective argument; and the attachment of a grading rubric clarifying faculty expectations, with point-values assigned to detailed indicators of effective reasoning and communication. Similarly, scaffolding will be built into the assessment by requiring students to revise those weaknesses in argument highlighted by the instructor in the grading rubrics, class discussions, and commented feedback. The importance of feedback and the value of revision, in this integrative approach to instruction, encourages the adoption of Boyer's (1990) "collaborative effort around teaching" (p. 80), and presents the opportunity to build an interdisciplinary network through learning communities or campus-wide, as advocated by Huber and Hutchings (2005, p. 68).

Instructors should also prepare students to research definitions by stressing the link between making sense of specialized vocabulary and mathematical (or other specialized) concepts. In both cases, understanding cannot be reached from a formal statement alone; it implies, and requires, the ability to paraphrase or recast the formulation, and to apply it in different contexts. As such, "understanding definitions" is a creative act that can directly exercise the core competencies of critical, quantitative, and information literacy. To reinforce the links among these competencies and technological literacy, we further recommend having students refer explicitly to online sources and use technological resources to regularly argue and establish positions and evaluate the validity of claims. In our particular project, this emphasis applies to students' fitting of data to a given model (question 6); for example, they can be asked to find more recent data than that presented in the project tables, and to test whether the validity of the model built from project data still holds. They will also be invited to examine whether their original models are realistic over time, and to consider, for instance, the repercussions of an exponential model.

We were encouraged by the energy students brought to their reflections on the project, the accuracy of their mathematical projections and computations, and 
the integrity of their participation in the surveys, and we hope to build on the heightened civic awareness most revealed in their writing. Huber and Hutchings (2005) point out that "education in science, technology, engineering, and mathematics (STEM) has attracted a unique level of national attention... because of these disciplines' centrality to defense, health, the environment, and the economy" (p. 65). Thus, now especially, we feel it is imperative for educators to help students perceive the relevance of their studies in introductory mathematics and science courses; exploiting the connections between fields and competencies is key to achieving this result. Indeed, "teaching is...a dynamic endeavor involving all analogies," as Boyer (1990) notes in Scholarship Reconsidered, and at its best, involves "not only transmitting knowledge, but transforming it and extending it as well" (p. 23-24). With self-investment and a sense of progress beyond testperformance, students are able to see themselves as 'transformers and extenders' of knowledge and become more likely to perceive learning and career paths in STEM fields as real opportunities and achievable goals. As one student wrote in a concluding reflection on the project, "I feel like I really learned something, and I cannot wait to share this with everyone".

\section{References}

Bass, R. (1999, February). The scholarship of teaching: What's the problem? Inventio: Creative Thinking about Learning and Teaching, 1(1). Retrieved from http://doit.gmu.edu//archives/feb98/ randybass.htm

Betne, P. (2010, July 23). Project Quantum Leap and SENCER at LaGuardia Community College. Science Education and Civic Engagement: An International Journal, Summer 2010. Retrieved from

http://seceij. net/seceij/summer10/pr oject_quantum.html

Boyer, E. (1990). Scholarship reconsidered. Princeton: The Carnegie Foundation for the Advancement of Teaching

Huber, M., \& Hutchings, P. (2005). The advancement of learning. San
Francisco: The Carnegie Foundation for the Advancement of Teaching.

Mission Statement. LaGuardia Community College - City University of New York. http://www. lagcc.cuny.edu/About/Mi ssion-Statement/

Quantway. The Carnegie Foundation for the Advancement of Teaching. http://www.carnegiefoundation.org/q uantway

Schulman, L. (2005). Signature pedagogies in the professions. Daedalus, 134(3), 52-59.

Steen, L. (2004). Achieving quantitative literacy: An urgent challenge for higher education. Washington, D.C: The Mathematical Association of America. 


\section{Appendix}

The project is given below. The "Activity Overview" is meant to summarize the project, since it is open to use by all faculty members.

\section{Activity Overview}

In this project, students will engage in inquiry-based learning, collecting data about commodities and food commodity trading. They will also read two articles about the practice and effects of speculation on food prices, and do exercises on functionfitting using commodity prices. Three fitting problems are provided (one for linear, one for quadratic, and one for exponential). You will need to spend time in a computer lab to help students with this activity.

- Have students consult the two given websites (http://www.investorwords.com, and http://indexmundi.com/commodities) to learn about what commodities are.

- $\quad$ Before moving on to Reading \#1, have students answer questions 1 and 2. Question 2 is a discussion activity that will help to prepare students, in terms of vocabulary and concepts, for the readings and tasks that follow.

- Have students read Reading \#1: "People die from hunger while banks make a killing on food" by John Vidal, The Guardian. This article can be found at http://www.guardian.co.uk/globaldevelopment/2011/jan/23/food-speculation-banks-hunger-poverty. Have students answer question 3 in writing so that you can check their understanding, and see that they can compare and add information to their evolving understanding of the deregulation of food commodities trading after they have done Reading \#2.

- Have students read Reading \#2: "Rampant Speculation Inflated Food price Bubble" by Stephen Leahy, IPS News. The article can be found at http://ipsnews. net/news. asp?idnews $=54274$

- $\quad$ Have students answer Questions 4 to 7.

- Question 7 will require students to marshal evidence from the two readings and their mathematical results in support of their opinions about the deregulation of food commodities trading.

- Question 8, an ePortfolio reflection, will prompt students to think about their own level of political engagement, their own learning, and the ultimate usefulness of this project.

\section{Materials and Resources}

- Students are expected to retrieve information from online sites: http://www. investorwords.com, and http://indexmundi.com/commodities

- Reading \#1: Vidal, John. (2011, January 23). Food speculation: 'People die from hunger while banks make a killing on food.' The Guardian. Retrieved February 29, 2012 from http://www. guardian.co.uk/global-development/2011/jan/23/foodspeculation-banks-hunger-poverty

- Reading \#2: Leahy, S. Rampant Speculation Inflated Food Price Bubble. IPS News.net. Retrieved February 29, 2012 from http://ipsnews. net/news. asp?idnews $=54274$

\section{Questions}

1) a. Paraphrase the definition of "commodity" as shown at http://www.investorwords.com 
b. List the various categories of commodities displayed at http://www.indexmundi.com/commodities

2) Pre-Reading Group/Class Discussion

a. What does "speculation" mean? How is it different from "investment"?

b. What does "deregulation of global commodity markets" mean? Why do you think the US would deregulate food commodity trading?

c. What do the following words and phrases mean?

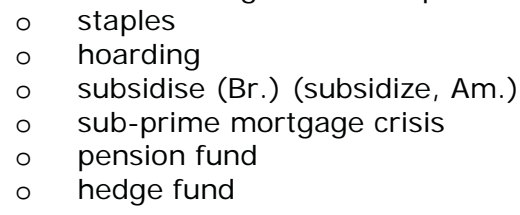

3) Answer the following questions about Article \#1: Food speculation: People die from hunger while banks make a killing on food

a. What is hedging? Give an example.

b. What is "deregulation of global commodity markets"? Why do you think the US deregulated food commodity trading?

c. How do experts at the UN explain the rise in food prices?

d. What theory does the author believe is behind the rise in food prices?

e. How did the speculation in food prices begin?

f. Why did the price of chocolate peak recently?

4) Answer the following questions about Article \#2: Rampant Speculation Inflated Food Price Bubble

a. What is the meaning of "bubble" in this reading?

b. The article illustrates "speculation on speculation" by examining how Farmer Brown's wheat futures contract can now be sold and resold, itself becoming a commodity. Can you foresee any potential problem(s) caused by such increasing speculation?

c. Why did the US deregulate food commodity trading? What was the result?

d. Why did food commodity speculation become a "hot ticket" in $2008 ?$

e. After spikes in the price of food in 2008 caused deadly famine and riots around the world, the UN cited rising food prices as a top threat to global security. Why did food prices spike again in 2010 ?

f. Why did multinational grain companies in the business of exporting wheat want Russia to ban wheat exports in 2010 ? 
g. According to GRAIN research, why weren't wheat exporters penalized for cancelling their export contracts with Egypt, Bangladesh, and other countries?

5) The following three graphs illustrate the 15-year price fluctuations in wheat, natural gas, and poultry, respectively. Use the graphs to answer the questions below:

a. Based on the graphs, which of the three commodities would you say is the most volatile? Which commodity would you say has experienced the greatest increase in volatility? Explain.

b. Estimate the price per pound of poultry (rounding to nearest cent) in February of 1996 and 2011, respectively. What was the average yearly rate of change in the price of poultry over this 15-year period? Based on this rate of change, how much will a pound of poultry cost in 2012?

c. John argues that natural gas prices should not be subject to regulation because they are relatively stable: The price per thousand cubic meters only increased from approximately $\$ 140$ fifteen years ago to $\$ 160$ today. Compute the corresponding percent increase in price. Does the graph support his claim?

d. Judy argues that natural gas prices are at least as volatile as those of wheat, and that both natural gas and wheat prices should be subject to regulation. She says wheat prices went from a low of approximately $\$ 160$ per metric ton to a high of approximately $\$ 440$ over the last five years. Compute the corresponding percent increase in price. Does the graph support her claim?

e. Class Discussion: What's your position on the regulation of commodities? Do you agree with John or Judy? Are commodity prices stable or volatile? Should they be monitored and regulated by an independent body? Find information from these graphs or others at http://www.indexmundi.com/commodities to support your point of view. Take notes. You will need these notes again for Exercise 8. 
15-Year Price Fluctuation in Wheat

U.S. dollars per metric ton

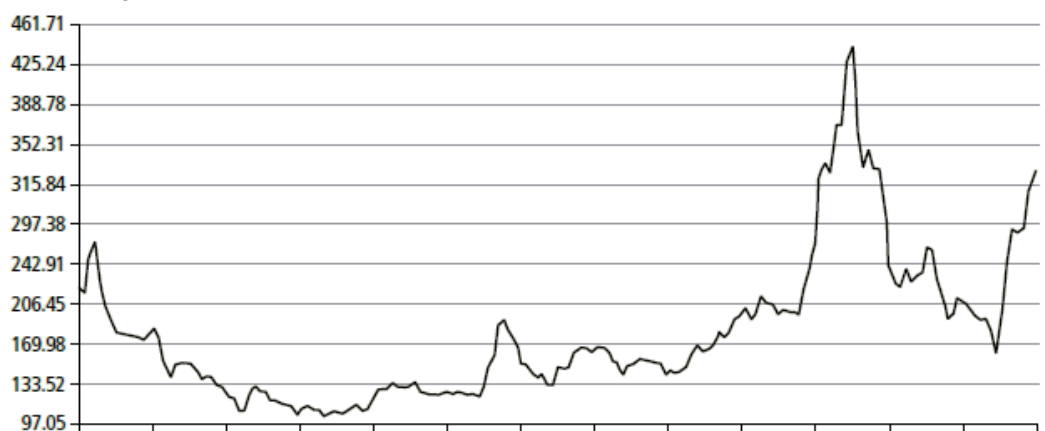

Feb'96 Feb'97 Feb'99 Feb'00 Feb'01 Feb'02 Feb'03 Feb'04 Feb'05 Feb'06 Feb'07 Feb'08 Feb'09 Feb'10 Source: IndexMundi.com. (n.d.) Wheat Daily Price. Retrieved March 2, 2011 from http://www.indexmundi.com/co mmodities/?commodity=wheat\&months $=180$

15-Year Price Fluctuation in Natural Gas

U.S. dollars per thousand cubic meters of gas

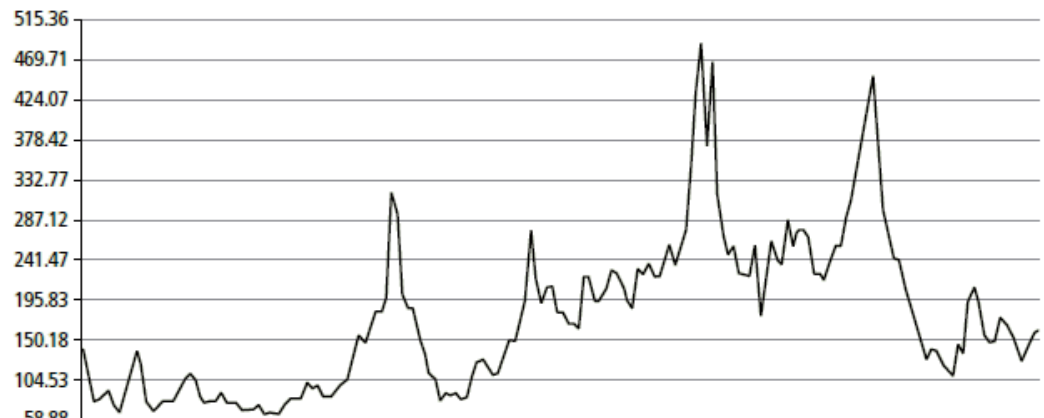

Feb'96 Feb'97 Feb'99 Feb'00 Feb'01 Feb'02 Feb'03 Feb'04 Feb'05 Feb'06 Feb'07 Feb'08 Feb'09 Feb'10 Source: IndexMundi.com. (n.d.) Natural Gas Monthly Price - US Dollars per thousand cubic meters of gas. Retrieved March 2, 2011 from http://www.indexmundi.com/commodities/?commodity=natural-gas\&months=1800

15-Year Price Fluctuation in Poultry

U.S. cents per pound

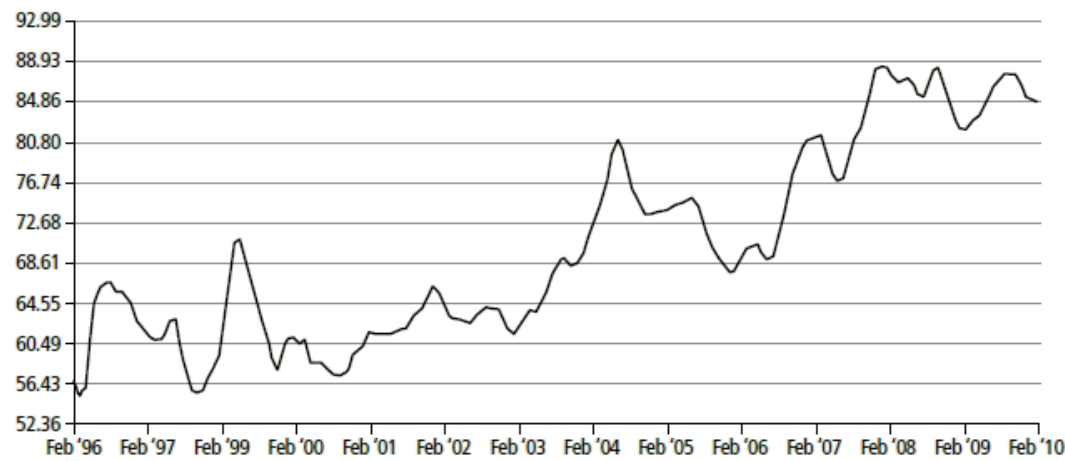

Source: IndexMundi.com. (n.d.) Poultry (chicken) Daily Price. Retrieved March 2, 2011 from

http://www.indexmundi.com/commodities/?commodity=chicken\&months=180 
Exercise with Excel:

a. Linear Fit

i. The following table shows the average monthly price of cocoa beans, in U.S. dollars per metric ton, between March 2009 and December 2009.

\section{Average monthly price of cocoa beans}

U.S. dollars per metric ton

\begin{tabular}{|l|r|}
\hline Mar 2009 & $2,493.98$ \\
\hline Apr 2009 & $2,541.70$ \\
\hline May 2009 & $2,554.60$ \\
\hline Jun 2009 & $2,699.61$ \\
\hline Jul 2009 & $2,805.48$ \\
\hline Aug 2009 & $2,956.66$ \\
\hline Sep 2009 & $3,149.51$ \\
\hline Oct 2009 & $3,372.50$ \\
\hline Nov 2009 & $3,379.33$ \\
\hline Dec 2009 & $3,517.54$ \\
\hline
\end{tabular}

Source: IndexMundi.com. (n.d.) Cocoa Beans Monthly Price - US Dollars per Metric Ton. Retrieved March 2, 2011 from http://www.indexmundi.com/ commodities/?commodity $=$ cocoa-beans\&months $=180$

i. Using Excel and starting with March 2009 as month \#0, graph the price of cocoa beans as a function of the number of each month (March $2009=0$, April $2009=1$, etc.)

ii. Fit the data to a linear function. Write the equation that the data fits to. Find the slope.

iii. If the trend had continued, what would the price of cocoa beans have been in February 2010?

b. Quadratic Fit

i. The following table shows the average monthly price of coconut oil, in U.S. dollars per metric ton, between August 2009 and January 2011. 
Average monthly price of coconut oil U.S. dollars per metric ton

\begin{tabular}{|l|r|}
\hline Aug 2009 & 747.00 \\
\hline Sep 2009 & 701.00 \\
\hline Oct 2009 & 706.00 \\
\hline Nov 2009 & 729.00 \\
\hline Dec 2009 & 768.00 \\
\hline Jan 2010 & 784.00 \\
\hline Feb 2010 & 798.00 \\
\hline Mar 2010 & 921.00 \\
\hline Apr 2010 & 939.00 \\
\hline May 2010 & 932.00 \\
\hline Jun 2010 & 993.00 \\
\hline Jul 2010 & $1,031.00$ \\
\hline Aug 2010 & $1,170.00$ \\
\hline Sep 2010 & $1,275.00$ \\
\hline Oct 2010 & $1,412.00$ \\
\hline Nov 2010 & $1,521.30$ \\
\hline Dec 2010 & $1,715.00$ \\
\hline Jan 2011 & $2,063.00$ \\
\hline
\end{tabular}

Source: IndexMundi.com. (n.d.) Coconut Oil Monthly Price - US Dollars per Metric Ton. Retrieved March 2, 2011 from http//www.indexmundi.com/ commodities/?commodity=coconut-oil \&months $=180$

i. Using Excel and starting with August 2009 as month \#0, graph the price of coconut oil as a function of the number of each month (August 2009=0, September 2009=1, etc.)

ii. Fit the data to a quadratic function (on Excel, use polynomial of order 2 ). Write the resulting equation.

iii. If the trend had continued, what would the price of coconut oil have been in July 2011 ?

c. Exponential Fit

i. Commodities are traded daily, their prices changing even by milliseconds-just like the prices of stocks in the stock market. Commodities fall into several categories: energy, beverages, cereals, fruits, meat, sugar, vegetable oils, etc... Commodities include many food categories, prompting debate as to whether the prices of commodities should be allowed to fluctuate without control. When the prices of such commodities as wheat or sugar increase dramatically, many in developing countries are left without access to food. The following table shows the average monthly price of cocoa beans, in U.S. dollars per metric ton, between June 2001 and October 2002. 
Average monthly price of cocoa beans U.S. dollars per metric ton

\begin{tabular}{|l|r|}
\hline Jun 2001 & 973.29 \\
\hline Jul 2001 & 965.32 \\
\hline Aug 2001 & $1,032.48$ \\
\hline Sep 2001 & $1,026.20$ \\
\hline Oct 2001 & $1,084.86$ \\
\hline Nov 2001 & $1,231.55$ \\
\hline Dec 2001 & $1,337.43$ \\
\hline Jan 2002 & $1,385.93$ \\
\hline Feb 2002 & $1,490.39$ \\
\hline Mar 2002 & $1,592.03$ \\
\hline Apr 2002 & $1,568.15$ \\
\hline May 2002 & $1,604.70$ \\
\hline Jun 2002 & $1,656.46$ \\
\hline Jul 2002 & $1,872.00$ \\
\hline Aug 2002 & $1,959.27$ \\
\hline Sep 2002 & $2,167.41$ \\
\hline Oct 2002 & $2,201.50$ \\
\hline
\end{tabular}

Source: IndexMundi.com. (n.d.) Cocoa Beans Monthly Price - US Dollars per Metric Ton. Retrieved March 2, 2011 from http://www.indexmundi.com/ commodities/?commodity $=$ cocoa-beans\&months $=180$

a. Using Excel and starting with June 2001 as month \#0, graph the price of cocoa beans as a function of the number of each month ( une $2001=0$, July $2001=1$, etc.)

b. Fit the data to an exponential function. Write the resulting equation.

c. If the trend had continued, what would the price of cocoa beans have been in February 2003?

7) Writing Task:

a. This project has shown you the results of the deregulation of food commodities trading. Do you think the trading of food commodities should be monitored and regulated by an independent agency, or do you think deregulation is preferable? Write an essay expressing your opinion. To strengthen your argument, refer to the ideas exchanged during the class discussion (see Question 5e), to the readings, and to the graphs in Exercise 4 or other graphs at 
http://www.indexmundi.com/commodities. Support your point of view with specific details.

8) ePortfolio Reflection (optional)

a. Has this activity affected your social concerns, political awareness or engagement in any way? If so, how? Will your own behavior be affected by this class activity? If so, how?

b. Before you graphed the tabled data in questions 6 and 7, what would you have predicted as future prices of coconut oil and cocoa beans?

c. What do you see in the graphs that you didn't see in the tabled data in questions 6 and 7 ?

d. Why do you suppose this project asked you to identify equations of graphs? Why is it useful to recognize equations from a given graph?

e. Why might it be useful to do the reverse-to be able to graph a given equation?

Dr. Reem Jaafar holds a Ph.D. in theoretical Physics from the CUNY Graduate School (2010). Dr. Jaafar received several fellowships from the CUNY Graduate Center including the very selective Mina Rees dissertation fellowship. Since 2010, Dr. Jaafar is an assistant professor at LaGuardia Community College of CUNY in the Math, Engineering and Computer Science Department where she co-founded the Math Society. She has co-authored 9 papers in peer-reviewed journals and has presented her work in theoretical physics and Mathematics pedagogy at over 10 conferences. Dr. Jaafar's current areas of research are nanomagnetism and mathematics pedagogy.

Yelena Baishanski is an Assistant Professor in LaGuardia's Department of Mathematics, Engineering and Computer Science. She completed her Ph.D. in Mathematics at the CUNY Graduate Center in 2010, having previously graduated from Université de Paris VII with a Licence de Mathématiques and from Harvard University with a B.A. in Comparative Literature. While pursuing her research in Number Theory and presenting at conferences at Bard, Stonybrook, and elsewhere, Yelena has actively invested in student excellence at LaGuardia, co-founding the LaGuardia Student Math Society with colleagues Drs. Yuan and Jaafar, and launching complementary pedagogical initiatives in her mathematics courses.

Volume $7 \bullet 2012$ 